\title{
Contribution to the Optimization of the Transient Stability of an Electric Power Transmission Network Using a Universal Power Flow Compensator Controlled by a Three-Stage Inverter
}

\author{
Koko Koko Joseph ${ }^{1}$, Nneme Nneme Léandre1, Ndjakomo Essiane Salomé2 \\ ${ }^{1}$ Laboratory of Computer and Automatic Engineering, UFD of Engineering Sciences, ENSET, University of Douala, Douala, Cameroon \\ ${ }^{2}$ Higher Normal School of Technical Education ENSET of EBOLOWA, University of Yaoundé, Yaoundé, Cameroon \\ Email: kokojoseph469@yahoo.fr, leandren@gmail.com, salomendjakomo@gmail.com
}

How to cite this paper: Joseph, K.K., Léandre, N.N. and Salomé, N.E. (2020) Contribution to the Optimization of the Transient Stability of an Electric Power Transmission Network Using a Universal Power Flow Compensator Controlled by a Three-Stage Inverter. World Journal of Engineering and Technology, 8, 675-688. https://doi.org/10.4236/wjet.2020.84048

Received: August 26, 2020

Accepted: November 6, 2020

Published: November 9, 2020

Copyright $\odot 2020$ by author(s) and Scientific Research Publishing Inc. This work is licensed under the Creative Commons Attribution International License (CC BY 4.0).

http://creativecommons.org/licenses/by/4.0/

\begin{abstract}
The use of an electrical network as close as possible to its limits can lead to its instability in the event of a high amplitude disturbance. The damping of system oscillations can be achieved by conventional means of voltage and speed regulation but also by FACTS (Flexible AC Transmission Systems) devices, which are increasingly used in power networks. In this work, optimal control coordination between a hybrid power flow controller and a three-level inverter was used to improve the transient stability of a transmission line. The UPFC is a combination of a serial compensator (SSSC) and a parallel compensator (STATCOM) both connected to a DC-LINK DC bus. The SSSC acts as a voltage source for the network and injects a voltage that can be adjusted in phase and amplitude in addition to the network voltage; the STATCOM acts as a current source. The approach used is tested in the Matlab Simulink environment on a single machine network. Optimal controller tuning gives a better transient stability improvement by reducing the transport angle oscillations from $248.17 \%$ to $9.85 \%$.
\end{abstract}

\section{Keywords}

FACTS, UPFC, Three-Stage Inverter, PI, Power Transit, Transient Stability

\section{Introduction}

Electricity is a basic energy need whose access is recognized as a right. It has become indispensable in everyday life and represents an essential component for 
the development of a country. Therefore, the availability of this energy as well as the maintenance of the balance between production and consumption requires constant monitoring to ensure the quality of service (transmission problem), its security (protection problem) and its stability (regulation problem). Electrical networks until the last few years are controlled mechanically (capacitor bank, inductor, phase-shifting transformer...). These during the problems of wear and their relative slowness make them insufficient to respond effectively to these remarkable requirements. The rapid development of power electronics has a considerable effect in improving the operating conditions of electrical networks by improving the control of their parameters through the introduction of control devices based on very advanced power electronics components (GTO, IGBT) known under the acronym FACTS [1]. FACTS systems are recently discovered compensators that combine capacitor banks and inductors coils with power electronics converters. These compensators, depending on their connection to the grid, are distinguished into shunt, series and hybrid compensators such as: STATCOM, SSSC, UPFC respectively. This work complements the work of

TRAN Quoc Tuan [2] who worked on the control of power flow in a network using a UPFC. In his work, he has been able to demonstrate the ability of the PI regulator to control a UPFC to improve the stability of the network and to compensate the reactive power but for small variations. Our work is then based on the use of this universal controller but controlled by a three-level inverter applied to a highly disturbed network in the optimization of the transient stability of electric power transmission networks.

\section{Materials and Methods}

\subsection{Materials}

\subsubsection{Hypothesis}

To carry out our work, we made the following considerations: the generator and the switches of our converter will be assumed ideal, the line will be balanced, the voltage drops across the line represented by the reactance $X$, the inductance of the line is represented by the inductance $L$. the characteristics of the line are given in the following Table 1.

Subsequently, we will proceed with the modeling of the serial converter while knowing that for the parallel converter the principle will be the same.

\subsubsection{Dynamic Equations of the Series Compensator}

The application of Kirchhoff's laws [4]. To the meshes of the circuit in Figure 1 gives us the mathematical equations governing our system as follows:

Table 1. Characteristics of the studied line [3].

\begin{tabular}{ccccccc}
\hline$U(\mathrm{KV})$ & $F(\mathrm{HZ})$ & $L(\mathrm{~km})$ & $R(\mathrm{ohm})$ & $X(\mathrm{ohm})$ & $P(\mathrm{MW})$ & $Q(\mathrm{MVAR})$ \\
\hline 225 & 50 & 168 & 14.77 & 69.72 & 293 & 99 \\
\hline
\end{tabular}




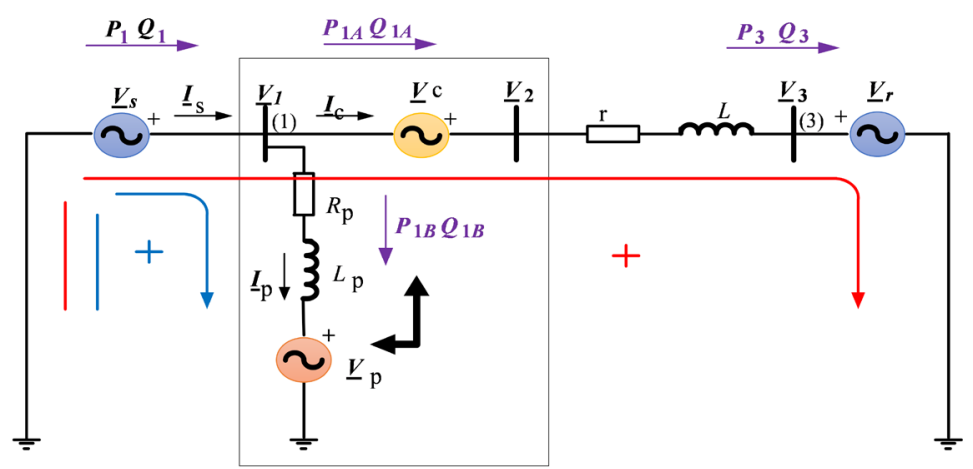

Figure 1. Physical representation of a UPFC converter connected to the network for modeling purposes.

$$
\left\{\begin{array}{l}
V_{s a}-V_{c a}-V_{r a}=r i_{s a}+L \frac{\mathrm{d} i_{s a}}{\mathrm{~d} t} \\
V_{s b}-V_{c b}-V_{r b}=r i_{s b}+L \frac{\mathrm{d} i_{s b}}{\mathrm{~d} t} \\
V_{s c}-V_{c c}-V_{r c}=r i_{s c}+L p \frac{\mathrm{d} i_{s c}}{\mathrm{~d} t}
\end{array}\right.
$$

In order to minimize the computing time, we have switched from the three-phase system to the two-phase system, i.e. from three-phase reference frames with coordinates $a, b$ and $c$, to two-phase reference frames with coordinates $\mathrm{d}$ and q. The transformation matrix is the following (Park's matrix) [5]:

$$
K=\sqrt{\frac{2}{3}}\left[\begin{array}{ccc}
\cos w t & \cos \left(w t-\frac{2 \pi}{3}\right) & \cos \left(w t+\frac{2 \pi}{3}\right) \\
\sin w t & \sin \left(w t-\frac{2 \pi}{3}\right) & \sin \left(w t+\frac{2 \pi}{3}\right) \\
\frac{1}{\sqrt{2}} & \frac{1}{\sqrt{2}} & \frac{1}{\sqrt{2}}
\end{array}\right]
$$

So the system becomes:

$$
\left\{\begin{array}{l}
V_{p s d}-V_{c d}-V_{r d}=r i_{p s d}+L \frac{\mathrm{d} i_{s d}}{\mathrm{~d} t}-w L i_{q} \\
V_{s q}-V_{c q}-V_{r q}=r i_{s q}+L \frac{\mathrm{d} i_{s q}}{\mathrm{~d} t}+w L i_{d}
\end{array}\right.
$$

Using the matrix representation on the system we have:

$$
\frac{\mathrm{d}}{\mathrm{d} t} \cdot\left[\begin{array}{l}
i_{s d} \\
i_{s q}
\end{array}\right]=\left[\begin{array}{cc}
\frac{-r}{L} & w \\
-w & \frac{-r}{L}
\end{array}\right] \cdot\left[\begin{array}{l}
i_{s d} \\
i_{s q}
\end{array}\right]+\frac{1}{L} \cdot\left[\begin{array}{l}
V_{s d}-V_{c d}-V_{r d} \\
V_{s q}-V_{c q}-V_{r q}
\end{array}\right]
$$

The equation above corresponds to our serial converter model. It will be used to build, under Simulink, the block that represents the serial part of the system. Therefore, this equation is represented by the following block diagram $(r=R)$ : (Figure 2) 


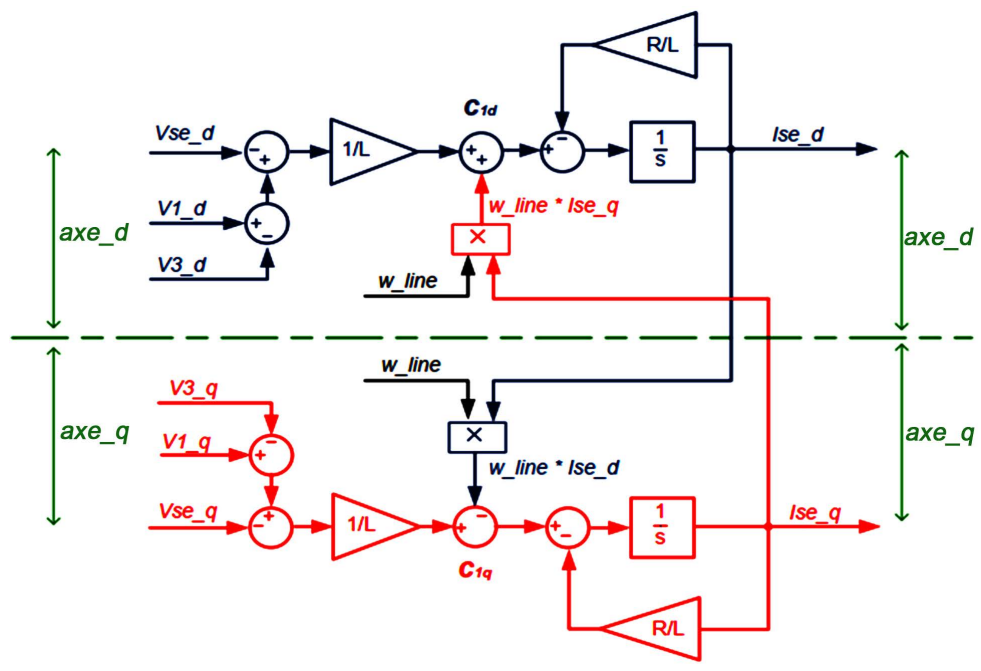

Figure 2. Block diagram of the serial circuit [6].

\subsubsection{Dynamic Equation of the Continuous Circuit}

The DC-Link connects the serial converter and the shunt converter of the UPFC. To model the DC-Link, we will use the single-phase model of the following converter (Figure 3).

We will first define the input/output relationships of our converters. We are going to assimilate them to a quadripole whose modulation function $w(t)$ connects their inputs and outputs in the following way:

\section{$>$ For the shunt converter}

The equation verified by the quadrupole is as follows:

$$
V_{e}=\omega_{e}(t) V_{i n} \text { and } I_{e}=\frac{1}{\omega_{e}(t)} I_{i n}
$$

Due to the independence of the current $I_{e}$ from the voltage $V_{i n}$ and since the current $I_{i n}$ does not depend on the voltage $V_{e}$ either, the matrix representation of the input system is therefore:

$$
\left[\begin{array}{l}
I_{e} \\
V_{e}
\end{array}\right]=\left[\begin{array}{cc}
\frac{1}{\omega_{e}(t)} & 0 \\
0 & \frac{1}{\omega_{e}(t)}
\end{array}\right] \cdot\left[\begin{array}{l}
I_{i n} \\
V_{i n}
\end{array}\right]
$$

In this quadrupole, the instantaneous power is preserved. The following relationship is therefore verified:

$$
V_{e} I_{e}=V_{i n} I_{\text {in }} .
$$

\section{$>$ For the serial converter}

In the same way as for the shunt, one can write:

$$
\left[\begin{array}{l}
I_{s} \\
V_{s}
\end{array}\right]=\left[\begin{array}{cc}
\frac{1}{\omega_{s}(t)} & 0 \\
0 & \frac{1}{\omega_{s}(t)}
\end{array}\right] \cdot\left[\begin{array}{c}
I_{\text {out }} \\
V_{\text {out }}
\end{array}\right]
$$




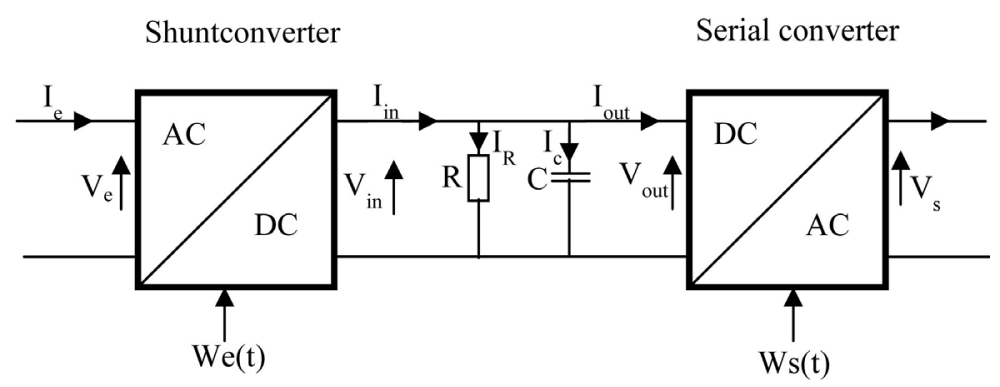

Figure 3. Diagram of the UPFC DC-link [7].

The equations verified by the DC-Link shown in the figure above are the following:

$$
\left\{\begin{array}{l}
\frac{\mathrm{d} U_{D C}}{\mathrm{~d} t}=\frac{1}{C} I_{C} \\
I_{C}=I_{\text {in }}-I_{R}-I_{\text {out }} \\
I_{R}=\frac{V_{\text {in }}}{R}
\end{array}\right.
$$

Because of the equality of tensions $U_{D C}, V_{\text {in }}$ and $V_{\text {out }}\left(U_{D C}=V_{\text {in }}=V_{\text {out }}\right)$, we obtain, from the previous equations, the following expression of $U_{D C}$ :

$$
\frac{\mathrm{d}\left(U_{D C}\right)^{2}}{\mathrm{~d} t}=-\frac{2}{R C}\left(U_{D C}\right)^{2}+\frac{2}{C} P_{S h}-\frac{2}{C} P_{S e}
$$

this equation will be used in MATLAB/SIMULINK to form a block having the following form: (Figure 4).

\subsubsection{Calculation of the Instantaneous Active and Reactive Powers of the} UPFC

Active and reactive power

$$
\begin{aligned}
& P s=\frac{3}{2}\left(V_{s d} i_{s d}+V_{s q} i_{s q}\right) \\
& Q s=\frac{3}{2}\left(V_{s q} i_{s d}+V_{s d} i_{s q}\right)
\end{aligned}
$$

\subsection{Methods}

Theoretically, UPFC should be treated as a multi-variable system because both serial and parallel converters are connected on one side to the transmission line and on the other side to the DC circuit and therefore each have two outputs. To facilitate the synthesis of the controllers, the two converters will be processed separately. There are several possible configurations to control this compensator. But before that, it is necessary to determine the references to control the device. There are several methods of identification of the references (control quantities): Method based on the principle of active current, Decoupled Watt-Var Method and Instantaneous Real and Imaginary Power Method. In this work we have adopted the Decoupled Watt-Var Method. The idea of this method comes from 


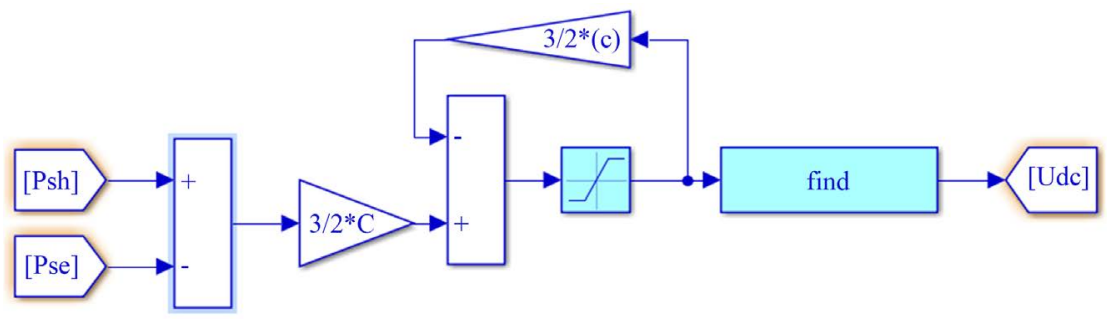

Figure 4. Block diagram of the DC-link.

the equations of the voltages obtained after the Park transformation, the problem of non-linearity is avoided in this method by considering only the fundamental quantities for the control of our system (Figure 5).

The principle of this method is to transform the measured quantities of current and voltage of the three phases on the two d-q axes using the Park transformation. Then the values of the active and reactive powers are imposed and the reference currents are calculated from these values (desired powers) and the values of the voltages measured by the two following equations:

$$
\begin{aligned}
& i_{s d}^{*}=\frac{2}{3} \cdot \frac{\left(p_{s}^{*} V_{s d}-q_{s}^{*} V_{s q}\right)}{V_{s d}^{2}+V_{s q}^{2}} \\
& i_{s q}^{*}=\frac{2}{3} \cdot \frac{\left(p_{s}^{*} V_{s q}+q_{s}^{*} V_{s d}\right)}{V_{s d}^{2}+V_{s q}^{2}}
\end{aligned}
$$

\subsubsection{Classic Decoupled Watt-Var Algorithm}

To drive our converter correctly, we need to remove this interdependence of the $\mathrm{d}$ and $\mathrm{q}$ axes. So we are going to create a decoupling block that will reproduce the coupling signal that we want to eliminate and then we are going to introduce this signal with the opposite sign at the input of our system. Our decoupling algorithm will therefore have the following form:

$$
\left\{\begin{array}{l}
X_{1}=\frac{1}{L s}\left(V_{d}-V_{s d}\right) \\
X_{2}=\frac{1}{L s}\left(V_{q}-V_{s q}\right)
\end{array}\right.
$$

With

$$
\left\{\begin{array}{l}
X_{1}=\left(K_{p}-\frac{K_{i}}{S}\right) \cdot\left(i_{s d}^{*}-i_{s d}\right)-w i_{s q} \\
X_{2}=\left(K_{p}-\frac{K_{i}}{S}\right) \cdot\left(i_{s q}^{*}-i_{s q}\right)-w i_{s d}
\end{array}\right.
$$

The association of the decoupling block and the system model will have the form of the following Figure 6 and Figure 7. We will only be left with our PI with a serial model of the system without coupling [9].

\subsubsection{Calculation of the Parameters of the Controllers Pi}

The classical proportional-integral regulator used in figure (9) ensures 


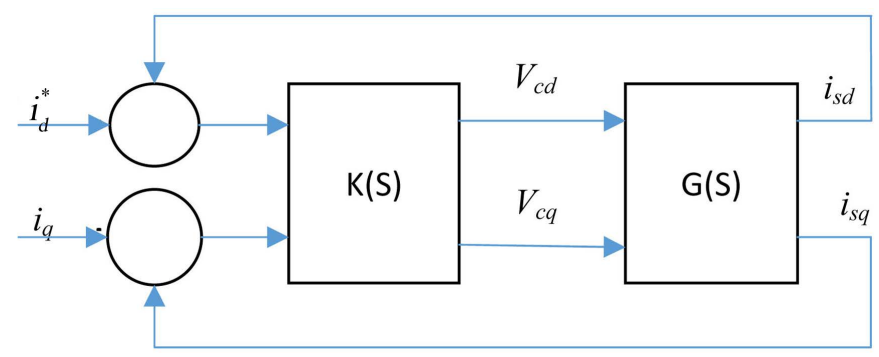

Figure 5. Control circuit of the UPFC [8].

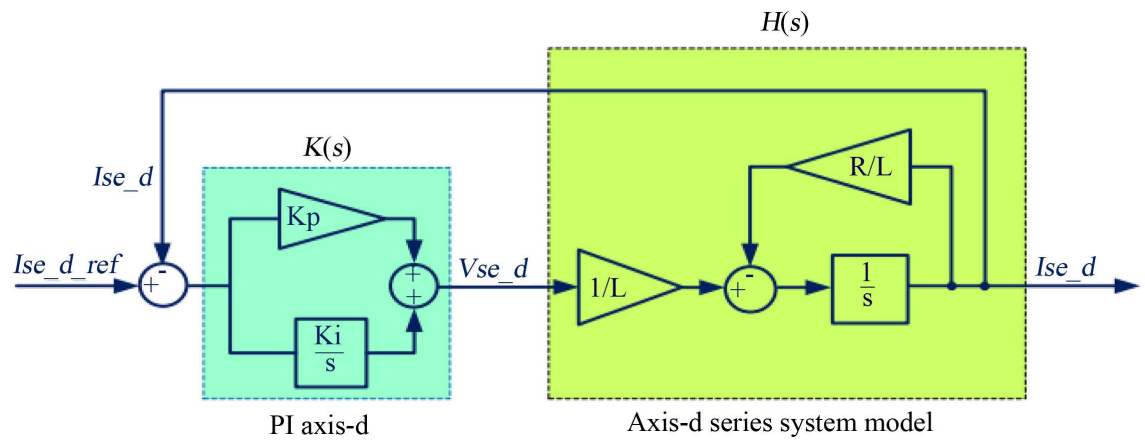

Figure 6. Diagram of the PI corrector and serial system model on the d-axis, after suppression of the disturbances of the voltages V1 $\mathrm{d}$ and V3 $\mathrm{d}$.

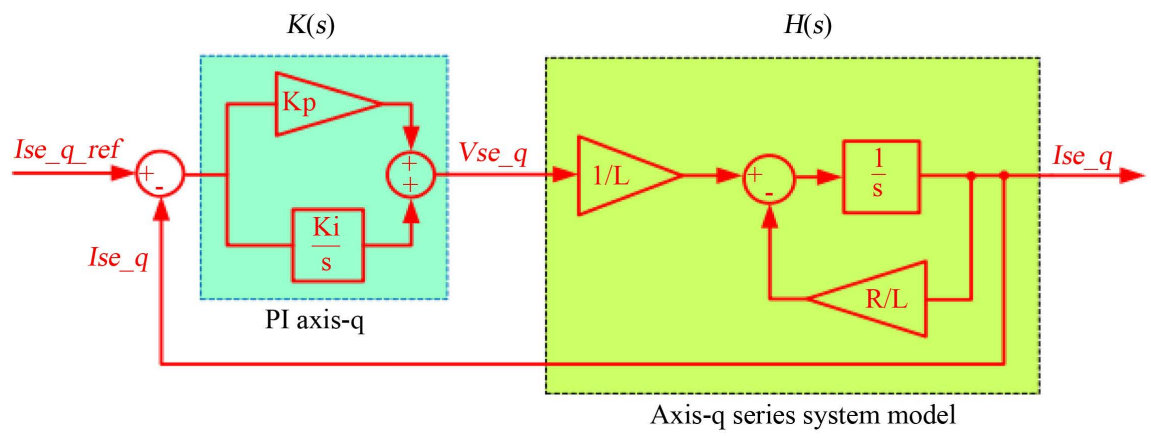

Figure 7. Diagram of the PI corrector and serial system model on the q-axis after suppression of the disturbances of the voltages $\mathrm{V} 1 \mathrm{q}$ and $\mathrm{V} 3 \mathrm{q}$.

maximum control of the error when its gains are maximal. It is also the most widely used regulator on an industrial scale due to its simplicity of implementation and its relatively low cost compared to advanced models [10]:

$$
K_{P}=K_{P} \max , K_{i}=K_{i} \max
$$

By introducing the following simple function linking the controller parameters

$$
\frac{K_{i}}{K_{p}}=\frac{R}{L}
$$

We obtain a first-order transfer function with a time constant of

$$
T=\frac{1}{K_{p}}
$$




$$
F_{11}(P)=F_{22}(P) \frac{K_{P}}{P+K_{P}}
$$

Given the above equations and a suitable choice of the value of $T(T T d)$ with $T d=0.1 \mathrm{~ms}$ (critical time of fault elimination). The gains $K_{P}$ and $K_{I}$ can be obtained as follows

$$
K_{P}=\frac{1}{T} \text { et } K_{I}=\frac{R}{L} \cdot \frac{1}{T}
$$

\subsubsection{IGBT Switch Control}

The purpose of the control is to generate the commands to open and close the switches so that the voltages created by the inverter are as close as possible to the reference voltage. By multiplying the number of intermediate levels, the amplitude of each rising or falling edge of the output voltage is reduced: the amplitude of the harmonic lines is therefore lower. In the specific case of PWM operation, the use of multilevel converters combined with a judicious control of the power components also makes it possible to suppress certain families of harmonic lines [11] (Figures 8-10).

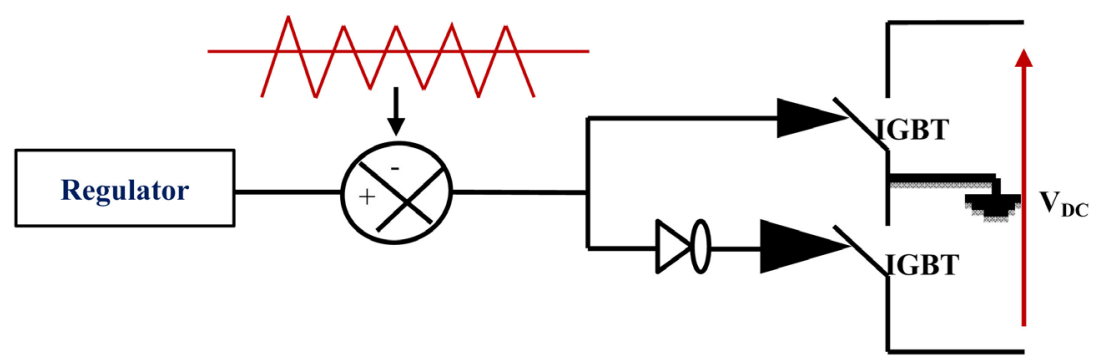

Figure 8. Principle of the MLI sinus-triangle.

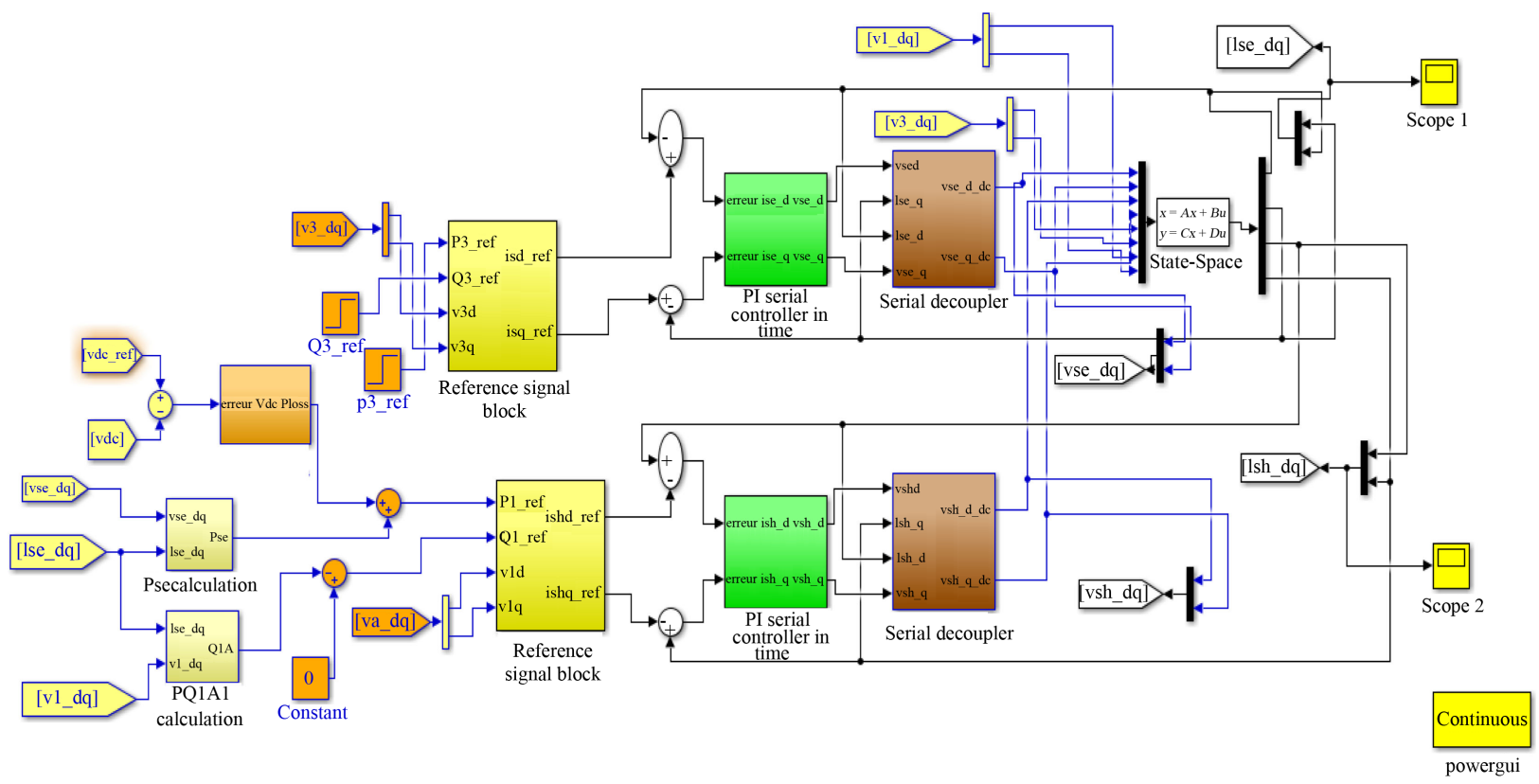

Figure 9. Adjustment circuit of the serial and parallel converters. 


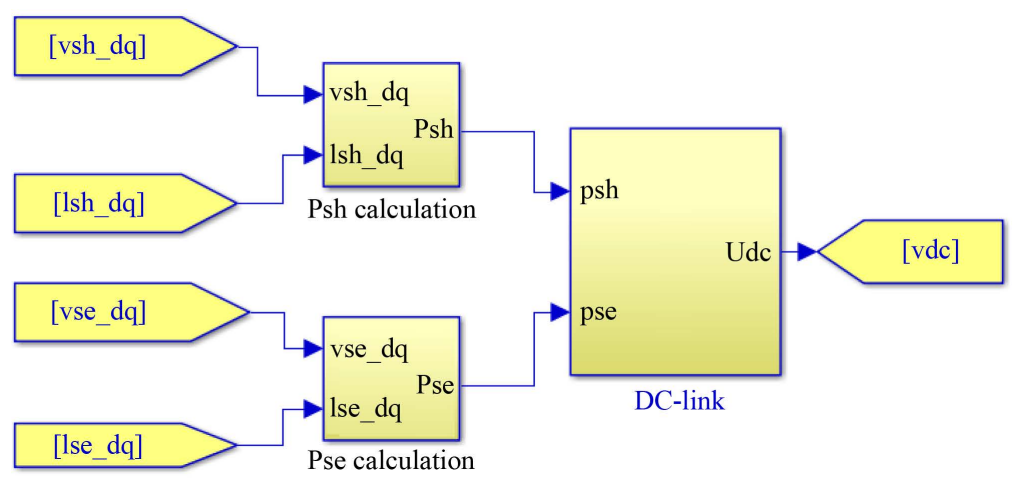

Figure 10. DC-LINK DC bus control circuit.

\section{Results and Discussion}

In this part, we started by highlighting the model of our network in the matlab Simulink environment as shown in Figure 11.

This network will be considered to be in a three-phase configuration change process: before, during and after contingency elimination.

\subsection{Simulation of the Undisturbed Network}

During the pre-fault phase, the network is usually in a stable steady state. Under these conditions, the network has a very specific transport angle $\delta$.

$$
P_{e}=\frac{V_{1} V_{2}}{X_{T}} \sin \delta
$$

This angle which corresponds to the equality between the electric power and the mechanic power according to the following formula:

$$
H \frac{\mathrm{d}^{2} \delta_{m}}{\mathrm{~d} t^{2}}=P_{a}=P_{m}-P_{e}
$$

This balance is characterized by a stability of active and reactive powers as well as currents and voltages as shown in the following Figure 12 and Figure 13.

$>$ Visualization of voltages

\section{$>$ Power display}

We see here that all the voltages are equal in amplitude (0.01) and offset from each other by 120 degrees.

\subsection{Simulation in the Presence of the Defect}

Figure 14 below represents a line in the presence of a contingency.

As soon as a disturbance occurs, the network enters the so-called transient fault conditions. The fault simulated in this example is a three-phase short circuit that we applied at time $t=0 \mathrm{~s}$ and which lasted $0.1 \mathrm{~ms}$. Under these conditions, the active power varies very quickly during this time, the variation of the mechanical power is relatively slow, therefore due to this slow response speed, a temporary deviation of power balance takes place causing the oscillations of the network parameters as we can see below (Figure 15 and Figure 16). 


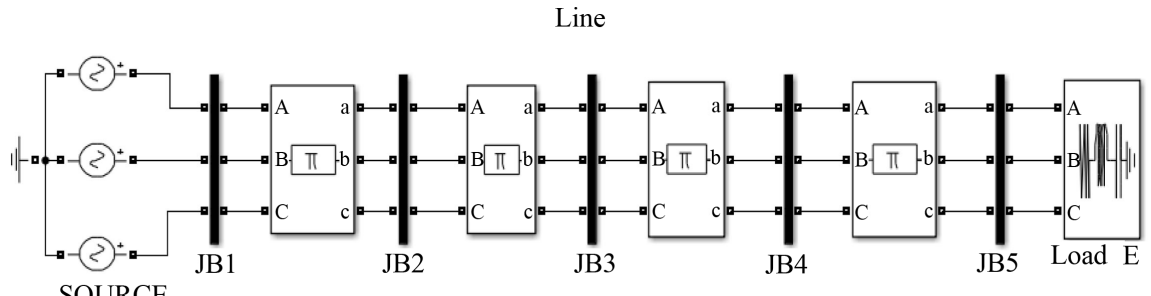

Figure 11. Empty line.

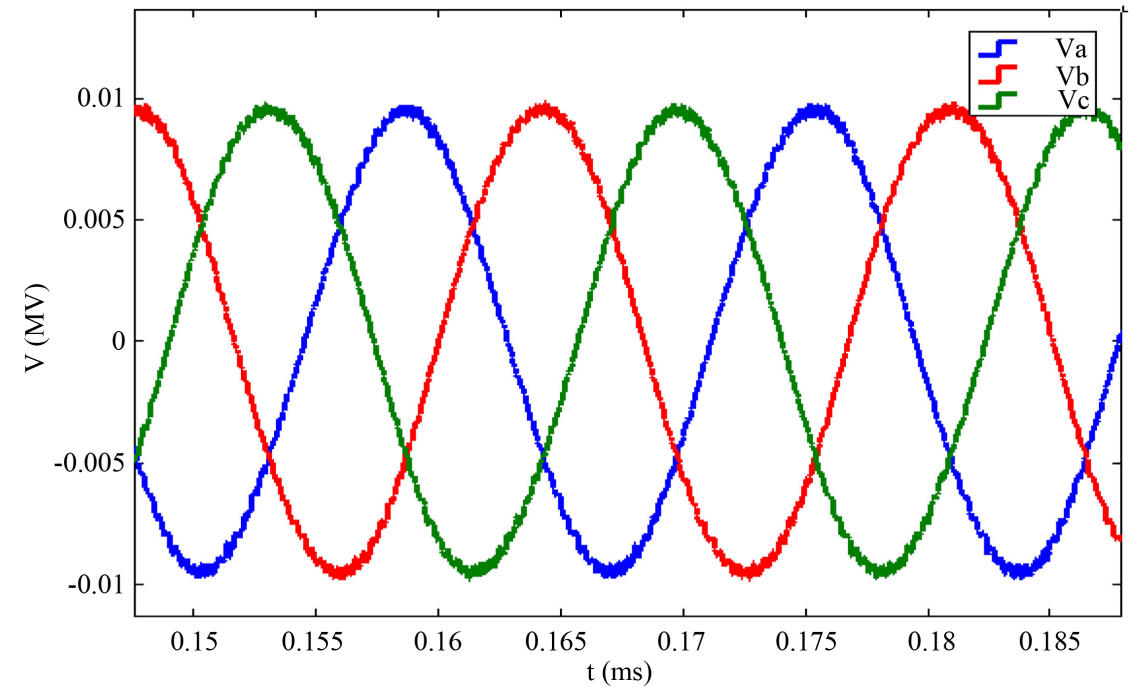

Figure 12. Steady-state network voltage.

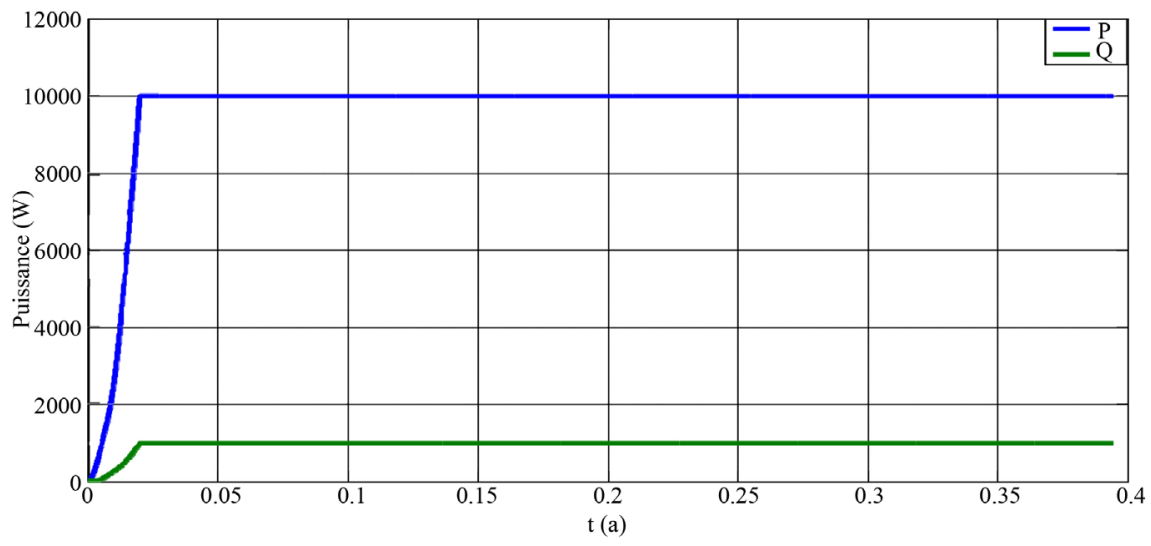

Figure 13. Power of the network in steady state.

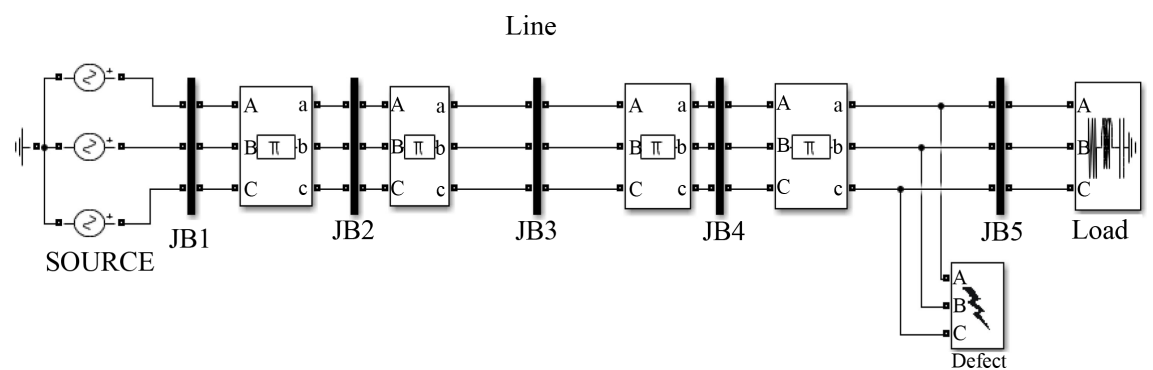

Figure 14. Diagram of a disturbed line. 


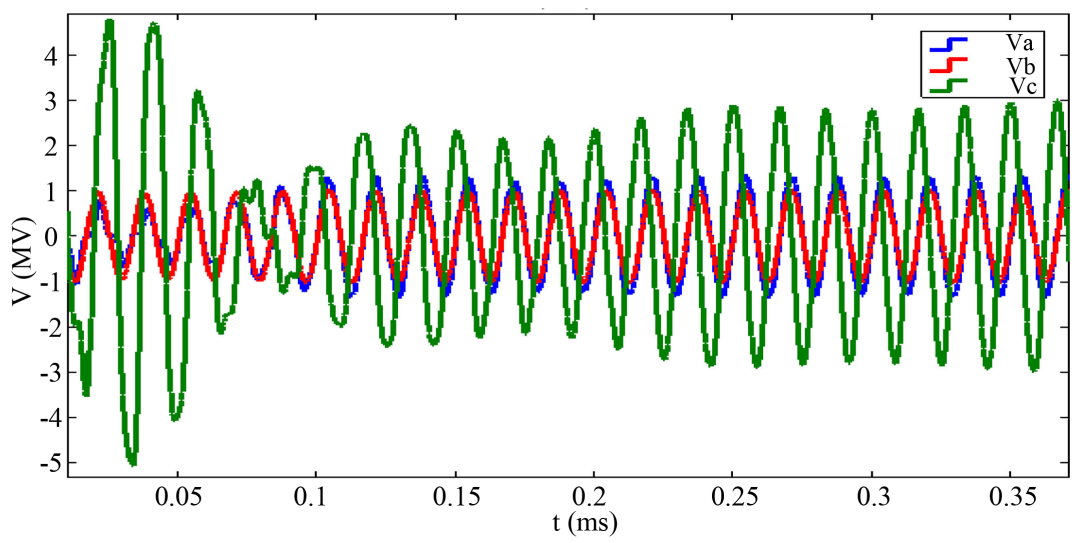

Figure 15. Network voltage under fault conditions.

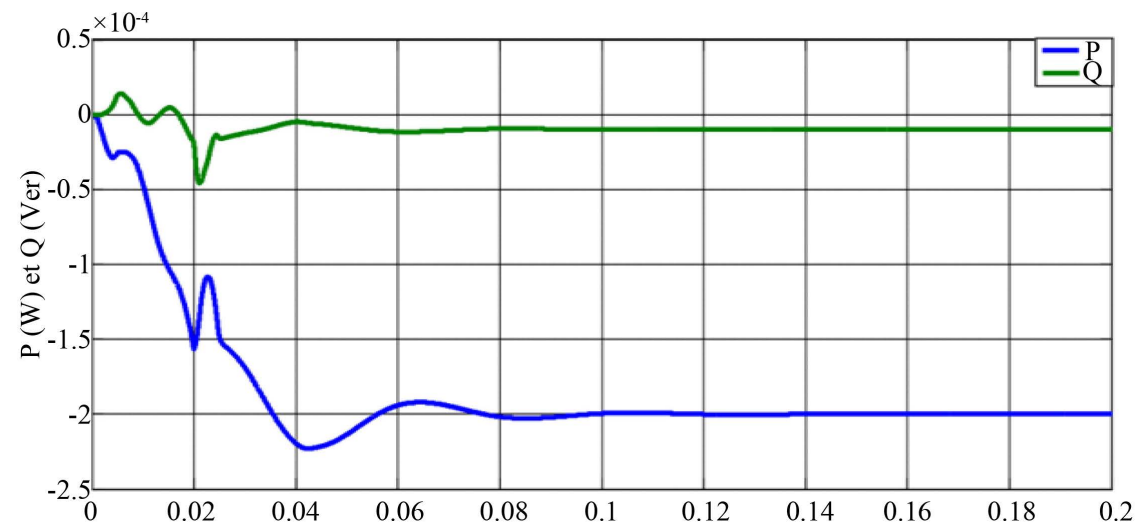

Figure 16. Power of the network under the right conditions.

\section{$>$ Visualization of the voltage}

$>$ Power display

If we come to the level of the first oscillation, we notice that the most disturbed phase has an amplitude which has gone from $0.01 \mathrm{~V}$ for the steady state to $5 \mathrm{~V}$ under fault conditions and it is therefore this rise in power of the parameters which often provokes the opening of the protection devices which in case of failure of the reclosing procedures will lead to a prolonged interruption as well as to the modification of the topology of the network (Table 2).

Although the system in this case is not seriously disrupted, its stability is still critical. In the absence of control, the system was subjected to unacceptable transport angle oscillations (up to 65 degrees). In this case the network tends towards instability, the course of the various network parameters is undamped oscillation (instability of several oscillations), and this is caused by the loss of the production-consumption equality.

\subsection{Simulation of the Fault in the Presence of UPFC}

The network plus our device is shown below: (Figure 17).

The behavior of the network in this configuration is as follows: (Figure 18 and Figure 19) 


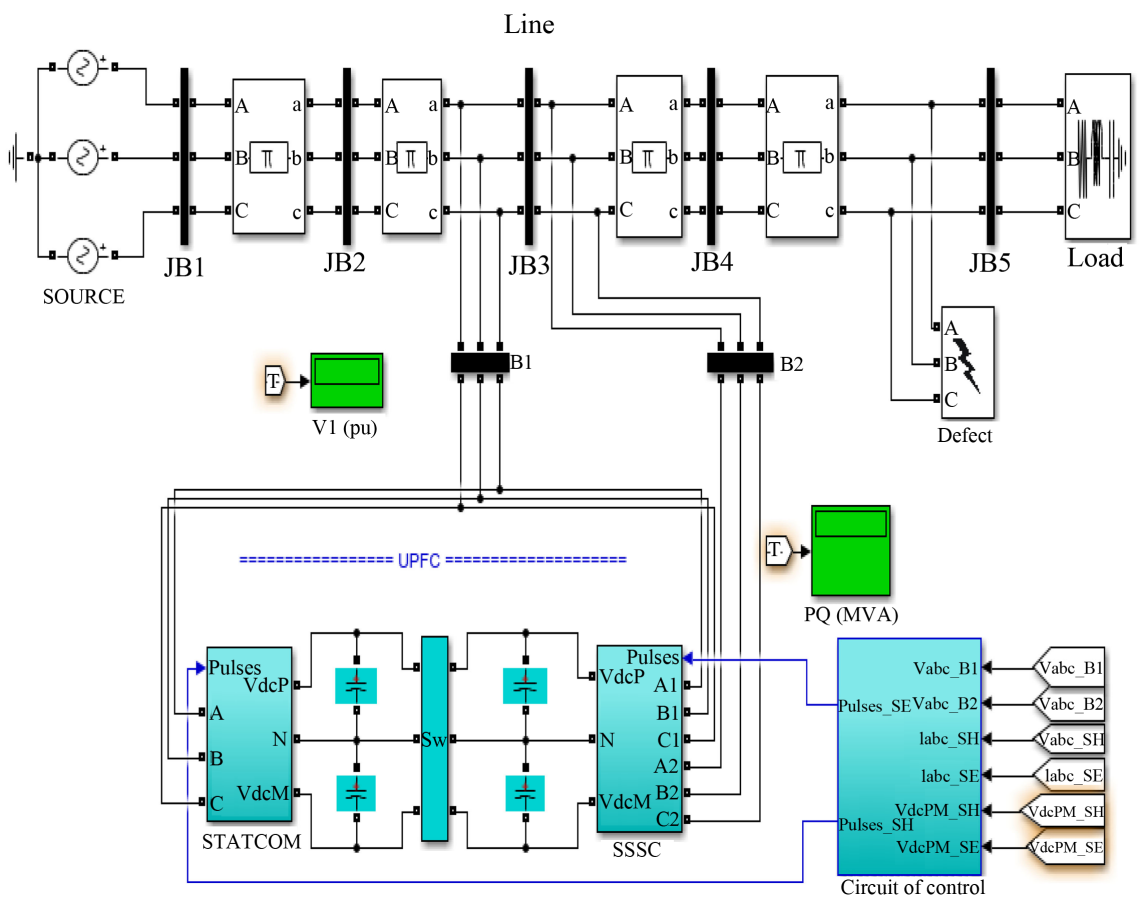

Figure 17. Network with UPFC under fault conditions.

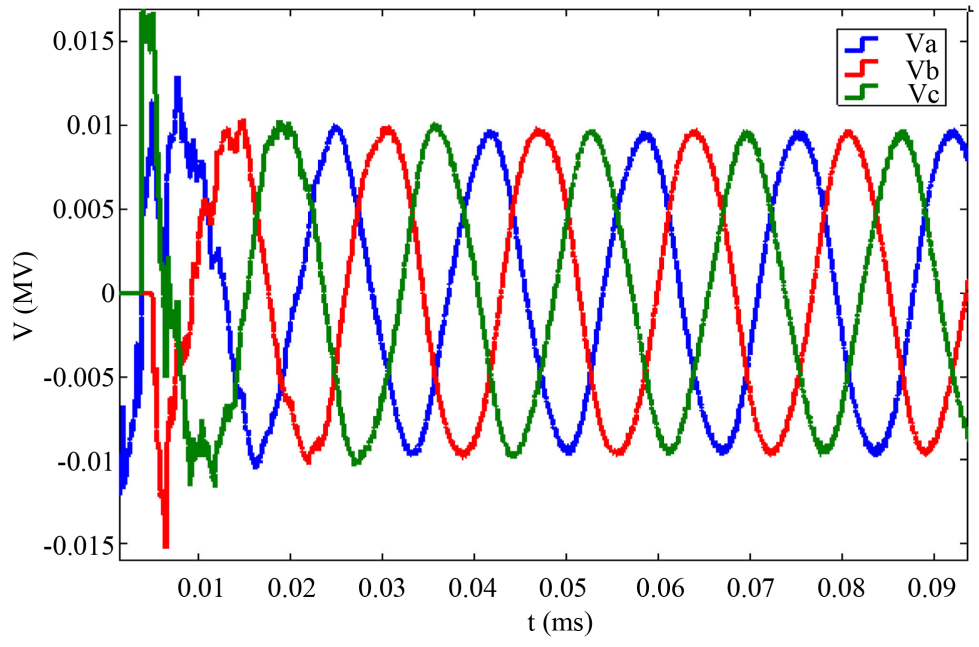

Figure 18. Network voltage under fault conditions.

\section{$>$ Visualization of the voltage}

\section{$>$ Power display}

We note that the appearance of a fault in the presence of the UPFC causes all the phases to oscillate in unison some time after the network regains a new stable operating regime, the oscillations generated by the disturbance fade with a damped amplitude, which increases the critical time of elimination of the fault. Another observation is that the system manages to recover its synchronism before the end of the fault, which approves the efficiency of the UPFC to converge the trajectories of the network interest parameters to an acceptable operating regime after a certain fault clearance time (Table 3 ). 


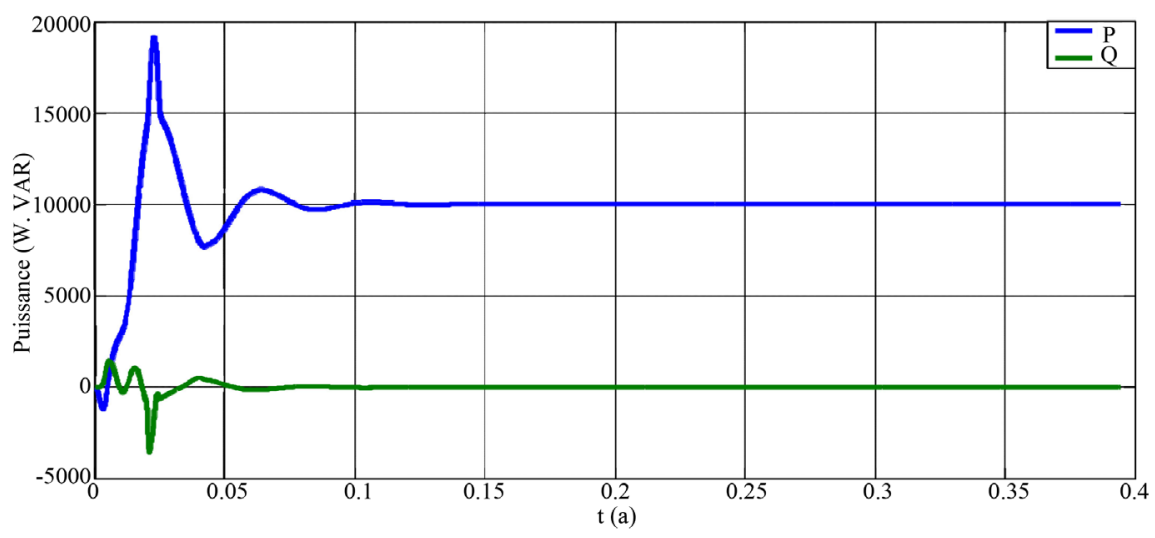

Figure 19. Power of the network under fault conditions.

Table 2. Network synthesis without regulator.

\begin{tabular}{ccccccc}
\hline \multicolumn{7}{c}{ STATE OF THE NETWORK WITHOUT CONTROLLER } \\
\hline Sizes & $\begin{array}{c}\text { Before } \\
\text { default }\end{array}$ & $\begin{array}{c}\text { In the presence } \\
\text { of the defect }\end{array}$ & $T d(\mathrm{~ms})$ & $\begin{array}{c}\text { After } \\
\text { default }\end{array}$ & Error & $\begin{array}{c}\text { Relative } \\
\text { error in \% }\end{array}$ \\
\hline$\varphi$ & 18.669 & 65 & & 0 & 46.331 & 248.17 \\
$P($ MW $)$ & 293 & 265.54 & 0.1 & 0 & 27.46 & 9.37 \\
$Q$ (MVAR) & 99 & 569.469 & & 0 & 470.469 & 470.22 \\
\hline
\end{tabular}

Table 3. Network synthesis with regulator.

\begin{tabular}{ccccccc}
\hline \multicolumn{7}{c}{ NETWORK STATUS WITH CONTROLLER } \\
\hline sizes & $\begin{array}{c}\text { Before } \\
\text { default }\end{array}$ & $\begin{array}{c}\text { In the presence } \\
\text { of the defect }\end{array}$ & $T d$ & $\begin{array}{c}\text { After } \\
\text { default }\end{array}$ & Error & $\begin{array}{c}\text { Relative } \\
\text { error in \% }\end{array}$ \\
\hline$\varphi($ degree $)$ & 18.669 & 16.83 & & 18.669 & 1.83 & 9.85 \\
$P($ MW $)$ & 293 & 281 & 0.1 & 293 & 12 & 4.09 \\
$Q($ MVAR $)$ & 99 & 85 & & 99 & 14 & 14.14 \\
\hline
\end{tabular}

\section{Conclusion}

The development of power electronics has improved the management of electrical networks by introducing a new concept by the power transmission systems called FACTS, with which the control of the active and reactive power flow, the increase of the load capacities of the lines as well as the improvement of the stability of the network are achieved and performed by the injection of the voltages (or current) of the converters designed with modern static switches. The study presented in this paper was part of this concept and focused on the improvement of the transient stability of an electrical network with a FACTS device called UPFC based on voltage inverters. The Integral Proportional Controllers used for the regulation of the quantities of this device brought us satisfactory results in terms of response time and damping of oscillations. This study has allowed us to predict this very advantageous device for electrical networks by demonstrating a major flexibility in the control of the majority of the network parameters, based 
on the MLI control of the converters which represents the basic component of this device. The reliability of these devices would be to use control based on FPGA technology.

\section{Conflicts of Interest}

The authors declare no conflicts of interest regarding the publication of this paper.

\section{References}

[1] Racz, L.Z. and Bokay, B. (1988) Power System Stability. Vol. 30, Ed Elsevier, Amsterdam.

[2] Quoc, T.T. (2000) Modélisation et amélioration des performances des réseaux électriques. Energie électrique. Institut Polytechnique de Grenoble-INPG.

[3] Lu, W. (2009) Optimal Load Shedding for the Prevention of Major Blackouts. Doctor De L'institut Polytechnique De Grenoble on July 6.

[4] Kundur, P. (1994) Power System Stability and Control. McGraw Hill Inc.

[5] Brogan, W.L., et al. (2000) Control Systems. The Electric Engineering Handbook, CRC Press LLC, Boca Raton.

[6] Crappe, M. (2003) Stability and Safeguarding of Electric Power Networks, Ed. Bermes Science Publication, Lavoisier.

[7] Pavella, M. and Murthy, P.G. (1994) Transient Stability of Power Systems: Theory and Practice, Library of Congress Cataloguing in Publication.

[8] Gholipour Shahraki, E. (2003) UPFC's Contribution to Improving the Transient Stability of Electrical Networks. Doctoral Thesis, Faculty of Sciences \& Techniques, Henri Poincaré University, Nancy-I.

[9] Hingorani, N.G. and Gyugyi, L. (2000) Understanding FACTS: Concepts and Technology of Flexible AC Transmission Systems. IEEE Press, New York.

[10] Passelergue, J.C. (1998) Interactions of FACTS Devices in Large Electrical Networks. Doctoral Thesis, Institut Nationale Polytechnique de Grenoble.

[11] IEEE/CIGRE Joint Task Force on Stability Terms and Definitions. Definition and Classification of Power System Stability. IEEE Transactions on Power Systems, 19, 1387-1401. https://doi.org/10.1109/TPWRS.2004.825981 